\title{
Mn-porphyrin Conjugated Au Nanoshells Encapsulating Doxorubicin for Potential Magnetic Resonance Imaging and Light Triggered Synergistic Therapy of Cancer
}

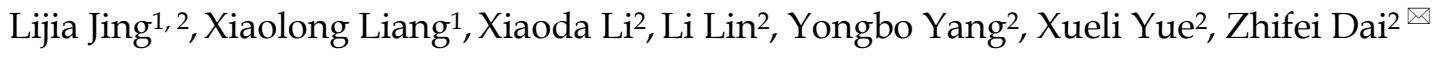 \\ 1. Department of Biomedical Engineering, College of Engineering, Peking University, Beijing 100871, China. \\ 2. School of Life Science and Technology. Harbin Institute of Technology, Harbin 150080, China.

\begin{abstract}
$\triangle$ Corresponding author: Prof. Zhifei Dai Corresponding-Author, E-mail: zhifei.dai@pku.edu.cn. Homepage: http://bme.pku.edu.cn/ $\sim$ daizhifei.
\end{abstract}

() Ivyspring International Publisher. This is an open-access article distributed under the terms of the Creative Commons License (http://creativecommons.org/ licenses/by-nc-nd/3.0/). Reproduction is permitted for personal, noncommercial use, provided that the article is in whole, unmodified, and properly cited.

Received: 2014.02.13; Accepted: 2014.05.05; Published: 2014.06.II

\begin{abstract}
A theranostic agent was successfully fabricated by the formation of Au nanoshell around poly(lactic acid) nanoparticles entrapping doxorubicin, followed by linking a Mn-porphyrin derivative on the Au shell surface through polyethylene glycol. The resulted agent exhibited excellent colloidal stability and long blood circulation time due to introducing polyethylene glycol. The grafting Mn-porphyrin onto the nanoparticle surface endowed a greatly improved relaxivity ( $r_{1}$ value of $22.18 \mathrm{mM}^{-1} \mathrm{~s}^{-1}$ of $\mathrm{Mn}^{3+}$ ), favorable for accurate cancer diagnosing and locating the tumor site to guide the external near infrared (NIR) laser irradiation for photothermal ablation of tumors. The in vitro experiments confirmed that the agent exhibited an efficient photohyperthermia and a light triggered and stepwise release behavior of doxorubicin due to the high NIR light absorption coefficient of Au nanoshell. The in vivo experiments showed that the combination of chemotherapy and photothermal therapy through such theranostic agent offered a synergistically improved therapeutic outcome compared with either therapy alone, making it a promising approach for cancer therapy. Therefore, such theranostic agent can be developed as a smart and promising nanosystemplatform that integrates multiple capabilities for both effective contrast enhanced magnetic resonance imaging and synergistic therapy.
\end{abstract}

Key words: Au nanoshell; porphyrin; photothermal therapy; chemotherapy; magnetic resonance imaging.

\section{Introduction}

Developing stimulus-responsive nanoparticles (NPs) for remote controlled cancer treatments has aroused widespread interest in nanomedicine [1]. Up to now, several physical stimulus, such as light, heat, ultrasound and magnetic field, have been successfully utilized as "remote controls" to trigger and regulate the nanoparticle based therapeutic process [2-5]. Photothermal therapy (PTT), a hyperthermia therapeutic methodology for cancer, has become one of research focuses due to its reasonable penetrating depth, minimal invasiveness and good controllability $[6,7]$. With the help of photo-absorbing agents, near-infrared (NIR) light penetrating into tumor region can be converted into heat for specific ablation of cancer cells without damaging nearby healthy tissues. A variety of nanomaterials, such as Au nanostructures (for example Au nanoshells [8-10], Au nanonords [11, 12] and Au nanocages [13-15]), carbon nanomaterials [16-19], polypyrrole nanoparticles [20], and copper sulfide nanoparticles [21-23], have been extensively 
explored as promising photo-absorbing agents for photothermally ablating cancer owing to the high NIR light absorption coefficient and favorable biocompatibility. Besides directly ablating tumor, NIR light mediated photothermal effect has also been utilized to trigger the release of therapeutic agents, such as anticancer drug and siRNA, for intelligently increasing their accumulation at tumor target and drastically decreasing side effect $[24,25]$. In most cases, the combined cancer treatment could offer a synergistically improved therapeutic outcome compared with either therapy alone [26].

As effective guidance for NIR light mediated cancer therapy, appropriate medical imaging modality is essential to identify the tumor size and location before therapy for adjusting the power, direction and range of external NIR laser, to monitor the treat procedure during therapy, and to assess the effectiveness after therapy. Among various imaging modalities, magnetic resonance imaging (MRI) is particularly attractive due to its advantages of noninvasive, high spatial resolution and three-dimensional imaging [27-29]. In addition, the sensitivity of MRI can be enhanced greatly by the utilization of contrast agents. Paramagnetic $\mathrm{Gd}^{3+}$ complexes are clinically favorable MRI contrast agents due to their high contrast ability $[30,31]$. However, the renal toxicities of widely used $\mathrm{Gd}^{3+}$ complexes have raised our concerns [32]. Iron oxide NPs are the first clinically used $T_{2}$ contrast agents [33], especially for imaging reticuloendothelial system (RES) organs like the liver, spleen and lymph nodes. Yet, iron oxide NPs induce a negative contrast which may be confused with areas of innate hypointensities, such as hemorrhage and blood clots, or interfered with magnetic susceptibility artifacts [34]. Manganese is an essential element for humans. Compared with other paramagnetic metal ions, manganese is less toxic and has relatively high electronic spins and fast water exchange rate [35]. As $T_{1}$ contrast agents, $\mathrm{Mn}$ and its derivatives have been demonstrated to be potential molecular MRI probes in cancer imaging due to their excellent stability, high longitudinal relaxivity and tumorous "preferential uptake" property [35, 36]. Nevertheless, nearly all paramagnetic metal complexes have short half-lives in vivo, leading to limited imaging time and poor imaging outcomes [37]. Therefore, we have pressing need to conquer such problems.

Poly(lactic acid) (PLA) has been approved by the U.S. Food and Drug Administration (FDA) for medical and clinical applications due to its outstanding biocompatibility and biodegradability. In the past decades, PLA based nanostructures have been widely investigated as efficient delivery systems for various therapeutic agents $[38,39]$. For most polymers, in- cluding PLA, glass transition temperature ( $\mathrm{Tg}$ ), which denotes the structural transition from glassy to rubbery state, is a characteristic property [40, 41]. PLA NPs with the molecular weight above $14 \mathrm{kDa}$ have been found to exhibit significant thermal-sensitive drug release behavior: very slow at physiological temperature but significantly accelerated under elevated temperature above their $\mathrm{Tg}$ [40].

Inspired by the remarkable thermal-sensitive property of PLA NPs, we made an effort to utilize the NIR light mediated photothermal effect to elevate the temperature of PLA matrix for triggering the release of inner loaded anticancer drug at tumor target, thus making it possible to achieve intelligent drug delivery as well as photothermal tumor ablation. For this purpose, doxorubicin (DOX) was loaded into PLA NPs (DOX@PLA NPs), followed by the formation of $\mathrm{Au}$ nanoshell on the surface of the DOX loaded PLA nanoparticles (DOX@PLA@Au NPs). Then, Mn-porphyrin (MnP) was covalently attached onto the $\mathrm{Au}$ nanoshell surface using monosuccinamide-polyethylene glycol(PEG)-thioctamide with the molecular weight of $3 \mathrm{kDa}$ as a spacer, resulting a multifunctional agent of DOX@PLA@Au-PEG-MnP NPs (Fig 1). Each component would play a different role. Au nanoshell could act as a photo-absorbing agent to convert NIR light into heat for selectively ablating cancer cells and triggering the release of DOX from inner PLA matrix. On the other hand, MnP could endow DOX@PLA@Au-PEG-MnP NPs with the capability to enhance MRI for effectively guiding the synergistic therapy. Introduction of the PEG spacers would greatly prolong the circulation time in vivo, thus facilitating biomedical applications of such agent. The physicochemical properties of DOX@PLA@Au-PEG-MnP NPs were characterized in terms of morphology, size distribution, drug release profile and MRI contrast behavior. The in vitro and in vivo anticancer activities of the agents were evaluated using HT-29 cells and HT-29 tumor bearing mice.

\section{Materials and methods}

\section{Chemicals and Materials}

Poly (DL-lactic acid) (DL-PLA, 80k MW, inherent viscosity 0.2-0.5 dL/g) and polyvinyl alcohol (PVA, 86-89\% hydrolyzed, 20k MW) were obtained from Shandong Medical Instrumental Institute and Alfa Aesar, respectively. Hydroxylamine hydrochloride $\left(\mathrm{NH}_{2} \mathrm{OH} \bullet \mathrm{HCl}\right)$ was obtained from Shanghai Shanpu Chemical. Poly (allylamine hydrochloride) (PAH, 56k MW), 2-(4-Amidinophenyl)-6-indolecarbamidine dihydrochloride (DAPI), 1-(3-Dimethylaminopropyl)-3-ethylcarbodiimide hydrochloride (EDC) and N-Hydroxysuccinimide (NHS) were ob- 
tained from Sigma-Aldrich. Hydrogen tetra-chloroaurate (III) hydrate $\left(\mathrm{HAuCl}_{4} \bullet 4 \mathrm{H}_{2} \mathrm{O}\right)$ and sodium borohydride $\left(\mathrm{NaBH}_{4}\right)$ were obtained from Sino Reagent, China. Doxorubicin hydrochloride was obtained from Beijing Huafeng United Technology Co. Dialysis membrane was obtained from Spectrum Laboratories Inc. (molecular weight cut-off $12,000-14,000)$. All other chemicals and reagents were of analytical grade.

\section{Synthesis of MnP and PEG spacer}

$\mathrm{MnP}$ was synthesized according to our reported method [42]. PEG spacer of monosuccinamide-polyethylene glycol-thioctamide was synthesized according to the following procedure (Supplementary Material: Fig S1). Firstly, $\mathrm{NH}_{2}-\mathrm{PEG} 3000-\mathrm{NH}_{2}$ (500mg, $0.15 \mathrm{mmol}$ ) and thioctic acid $(35 \mathrm{~m} \mathrm{~g}, 0.15$ $\mathrm{mmol}$ ) were dissolved in $20 \mathrm{~mL}$ anhydrous dichloromethane (DCM), followed by adding dicyclohexylcarbodiimide (DCC) $(70 \mathrm{mg}, 0.3 \mathrm{mmol})$ at $0{ }^{\circ} \mathrm{C}$. The resulting solution was stirred overnight at room temperature. When the reaction finished, precipitate was removed by filtration, then the filtrate was concentrated under reduced pressure and isolated via silica gel chromatography using 80:20:1 $\left(\mathrm{CHCl}_{3} / \mathrm{CH}_{3} \mathrm{OH} / \mathrm{NH}_{4} \mathrm{OH}\right)$ as eluent. The resulting product $(200 \mathrm{mg})$ and succinic anhydride $(20 \mathrm{mg})$ were dissolved in $20 \mathrm{~mL}$ anhydrous tetrahydrofuran. After stirring at $80^{\circ} \mathrm{C}$ for $10 \mathrm{~h}$, the mixture was evaporated and dissolved in $2 \mathrm{~mL} \mathrm{CH}_{2} \mathrm{Cl}_{2}$, then precipitated from diethyl ether at $-20^{\circ} \mathrm{C}$. Finally, the PEG spacers were isolated via silica gel chromatography using 80:20 $\left(\mathrm{CHCl}_{3} / \mathrm{CH}_{3} \mathrm{OH}\right)$ as eluent. Chemical structures were analyzed by ${ }^{1} \mathrm{H}-\mathrm{NMR}$ spectroscopy (Supplementary Material: Fig S2 and S3).

\section{Preparation of DOX loaded PLA nanoparticles (DOX@PLA NPs)}

Briefly, 100mg PLA, a certain amount of DOX and excess triethylamine (quadruple the amount of DOX) were dissolved in $20 \mathrm{ml}$ of DCM. Resulted organic phase was mixed with $40 \mathrm{ml} 2 \%$ (w/v) PVA continuous phase. Then, the mixture was emulsified by probe sonication for $1 \mathrm{~min}$ (Sonicator 4000, Misonix) under $100 \%$ output amplitude setting. After evaporation of the organic solvent by magnetic stirring, the nanoparticles were obtained by centrifugation at $15,000 \mathrm{rpm}$, washing three times by DI water, and lyophilization $\left(-55^{\circ} \mathrm{C}, 72 \mathrm{~h}\right)$ using a freeze dryer (TFD5505, Ilshin Lab, Korea).

\section{Preparation of citrate-stabilized Au nanopaticles}

Citrate-stabilized Au nanoparticles with an average diameter of about $3 \mathrm{~nm}$ were prepared according to the reported method [8]. Briefly, $1.0 \mathrm{~mL}$ of $\mathrm{HAuCl}_{4} \bullet 4 \mathrm{H}_{2} \mathrm{O}$ aqueous solution $(1 \%, \mathrm{w} / \mathrm{v})$ and 1.0 $\mathrm{mL}$ of sodium citrate solution $(1 \%, \mathrm{w} / \mathrm{v})$ were added into $100 \mathrm{~mL}$ DI water with vigorous stirring for $1 \mathrm{~min}$, followed by adding $\mathrm{NaBH}_{4}(1.0 \mathrm{~mL}, 0.075 \% \mathrm{w} / \mathrm{v})$ in sodium citrate $(1 \% \mathrm{w} / \mathrm{v})$ solution and continuously stirring for $5 \mathrm{~min}$.
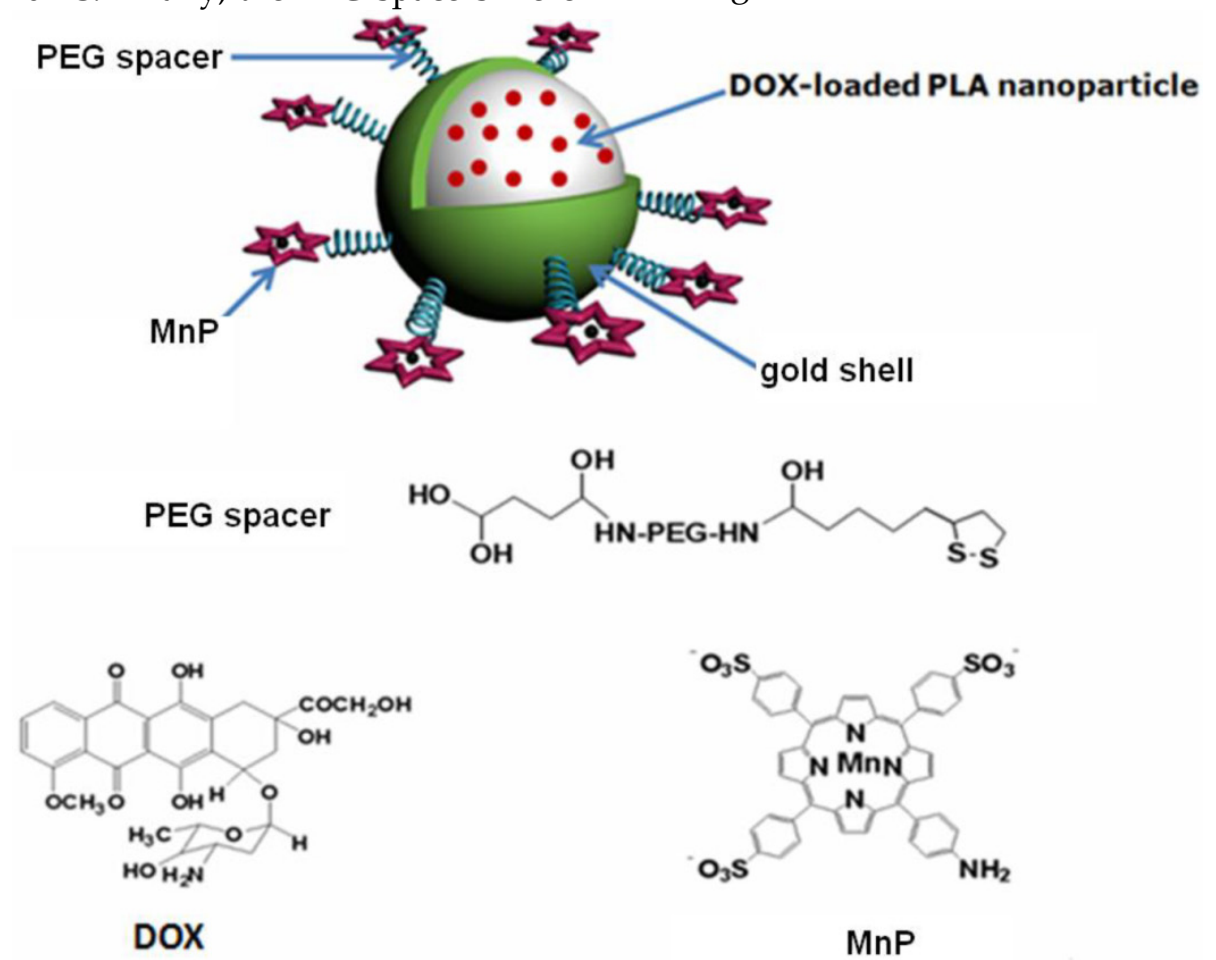

Figure I. Structural illustration of DOX@PLA@Au-PEG-MnP NPs. 


\section{Preparation of DOX@PLA@Au NPs}

100 mg of DOX@PLA NPs were suspended in 20 $\mathrm{mL}$ PAH solution $(1.0 \mathrm{mg} / \mathrm{mL}$ in $0.5 \mathrm{~mol} / \mathrm{L} \mathrm{NaCl}$ aqueous solution). After magnetic stirring for $10 \mathrm{~min}$, the PAH coated DOX@PLA NPs were centrifuged at $15000 \mathrm{~g}$ for $20 \mathrm{~min}$ and washed by DI water, then mixed with $200 \mathrm{~mL}$ citrate-stabilized Au nanopaticles $(\mathrm{Au} \mathrm{NPs})$ aqueous solution. After repeated adsorption/centrifuge/wash step, the resulted $\mathrm{Au}$ NPs coated DOX PNPs were poured into $\mathrm{HAuCl}_{4} \bullet 4 \mathrm{H}_{2} \mathrm{O}$ solution $(12 \mathrm{~mL}, 1 \% \mathrm{w} / \mathrm{v})$ under magnetic stirring. Then, freshly prepared $\mathrm{NH}_{2} \mathrm{OH} \bullet \mathrm{HCl}$ solution $(2 \mathrm{~mL}$, $0.5 \mathrm{~mol} / \mathrm{L}$ ) was added dropwise. The mixture was further stirred for about $30 \mathrm{~min}$ to allow the reduction of $\mathrm{HAuCl}_{4}$ to form $\mathrm{Au}$ nanoshell on the surface of DOX@PLA NPs.

\section{Preparation of DOX@PLA@Au-PEG-MnP NPs}

$100 \mathrm{mg}$ of monosuccinamide-polyethylene glycol-thioctamide, $2 \mathrm{mg}$ of $\mathrm{NaBH}_{4}$ and $20 \mathrm{mg}$ of DOX@PLA@Au NPs were mixed in 10 mL DI water. The resulting solution was dispersed by sonication for $2 \mathrm{~min}$ and stirred at room temperature for another $6 \mathrm{~h}$, then centrifuged at $15000 \mathrm{~g}$ for $20 \mathrm{~min}$ and washed by DI water for 3 times to obtain purified pegylated DOX@PLA@Au NPs. Afterward, the pegylated NPs were mixed with $2 \mathrm{mg} \mathrm{MnP}$ with one amino group per molecule, 3mg 1-(3-Dimethylaminopropyl)-3ethylcarbodiimide hydrochloride (EDC) and $2 \mathrm{mg}$ $\mathrm{N}$-Hydroxysuccinimide (NHS) in $10 \mathrm{~mL}$ DI water. The resulting solution was stirred at room temperature for $6 \mathrm{~h}$, then centrifuged at $15000 \mathrm{~g}$ for $20 \mathrm{~min}$ and washed by DI water to obtain DOX@PLA@Au-PEG-MnP NPs.

\section{Characterization}

FEI Quanta 200 scanning electron microscope (SEM) and FEI Tecnai G2 Sphera transmission electron microscope (TEM) were used to observe the morphology and structure of the nanoparticles. The size distributions and zeta potentials of the nanoparticles were evaluate using a 90Plus/BI-MAS instrument (Brookhaven Instruments Co., U.S.A). The $\mathrm{UV} / \mathrm{Vis}$ absorption spectra of the nanoparticles were obtained by a Varian 4000 UV-Vis spectrophotometer. Both $\mathrm{Au}$ and $\mathrm{Mn}$ contents of the obtained DOX@PLA@Au-PEG-MnP NPs was determined by inductively coupled plasma optical emission spectrometry (ICP-OES) after decomposing the nanocomposite by aqua regia.

\section{Photohyperthermic effect of DOX@PLA@Au- PEG-MnP NPs}

The nanoparticle dispersions of different concentrations in quartz cuvettes were irradiated by con- tinuous-wave diode NIR laser (Xi'an Minghui Optoelectronic Technology, China) with a center wavelength of $808 \pm 10 \mathrm{~nm}$ and output power of $2 \mathrm{~W}$ for 10 min. The temperature was measured by a digital thermometer with a thermocouple probe every $10 \mathrm{~s}$. DI water and RPMI 1640 were also exposed to the laser light for comparison.

\section{DOX loading and releasing}

To investigate the drug loading content, DOX@PLA@Au-PEG-MnP NPs were suspended in DMSO and irradiated by NIR laser $(808 \pm 10 \mathrm{~nm}, 2 \mathrm{~W})$ to quickly dissolve the inner PLA matrix. After centrifugation, the content of DOX in supernatant was determined using a fluorescence spectrophotometer (Varian Cary Eclipse). To investigate the DOX release pattern under NIR light irradiation or not, $5 \mathrm{mg}$ of DOX@PLA@Au-PEG-MnP NPs was suspended in 2 $\mathrm{mL}$ of phosphate buffered saline (PBS) $(10 \mathrm{mM}, \mathrm{pH}$ 7.4 ), sealed in dialysis bag and immersed in $20 \mathrm{~mL}$ of PBS, then exposed with or without NIR light at output power of $2 \mathrm{~W}$ at $37{ }^{\circ} \mathrm{C}$ under moderate shaking. In addition, the release pattern of DOX from DOX@PLA NPs was also investigated. The amount of released DOX was monitored at regular time intervals. The release test was performed in triplicate to calculate a mean value and standard deviation.

\section{Elimination of DOX@PLA@Au-PEG-MnP NPs from the circulation}

Three male Wistar rats (180-200 g) were intravenously injected with $500 \mu \mathrm{L}$ of DOX@PLA@Au-PEG-MnP NPs at $3 \mathrm{mg} / \mathrm{mL}$ (a dose of about $30 \mathrm{mg} / \mathrm{kg})$ and blood samples $(0.5 \mathrm{~mL})$ were collected at the time points of $0.5,1,1.5,2,4,8,12,24$ and $48 \mathrm{~h}$. The pharmacokinetics profile of DOX@PLA@Au-PEG-MnP NPs in bloodstream was finally evaluated by measuring the $\mathrm{Au}$ content in blood over the course of $48 \mathrm{~h}$ via ICP measurements after decomposing the blood samples by aqua regia. The pharmacokinetic parameter was calculated using a Kinetica TM software package. The infinitesimal calculus method was used to estimate the plasma concentration-time curve from zero to time infinity $\left(\mathrm{AUC}_{0-\infty}\right)$, elimination half-life $\left(\mathrm{T}_{1 / 2}\right)$ and mean residence time (MRT), which are different from the traditional calculation method depending on the finite curve from several data points. Compared with the widely used model of mice, Wistar rats have about ten times the volume of blood, relative large vascular aperture, which may lead to the improved circulation time in our study. All the animal experiments were approved by institutional animal use committee and carried out ethically and humanely. 


\section{Cellular experiment}

HT-29 cells were cultured in RPMI-1640 medium with $10 \%$ fetal bovine serum (FBS) at the environment of $37{ }^{\circ} \mathrm{C}$ and $5 \% \mathrm{CO}_{2}$. To visualize the solo photothermal cytotoxicity, a total of $2 \times 10^{4}$ HT- 29 cells were plated in 96-well plates with $24 \mathrm{~h}$ incubation. Then, HT-29 cells were incubated with PLA@Au-PEG-MnP NPs with no DOX at the concentration of $0.2 \mathrm{mg} / \mathrm{mL}$ in 6 well-plate $(2.0 \mathrm{~mL}$ per well) for $2 \mathrm{~h}$, then washed with PBS (10mM, pH 7.4) and exposed to NIR laser $\left(1.5 \mathrm{~W} / \mathrm{cm}^{2}\right)$ for $10 \mathrm{~min}$, and finally stained with calcein acetoxymethyl ester (calcein AM). In addition, cells treated with no agent and no laser, or only agent (PLA@Au-PEG-MnP NPs), or only laser were investigated as comparison, respectively.

To investigate the synergistic antitumor effect, a total of $2 \times 10^{4}$ HT- 29 cells were plated in 96-well plates with $24 \mathrm{~h}$ incubation, and then exposed to free DOX, PLA@Au-PEG-MnP NPs and DOX@PLA@AuPEG-MnP NPs with various concentrations for $4 \mathrm{~h}$, respectively. Then, the cells were irradiated with NIR laser at an output power of $1.5 \mathrm{~W} / \mathrm{cm}^{2}$ for $10 \mathrm{~min}$. Cell viability was measured by standard MTT method after further $24 \mathrm{~h}$ incubation. In addition, to investigate the enhanced chemotherapy of DOX due to the accelerated release under the irradiation of NIR light, a total of $2 \times 10^{4}$ HT-29 cells were plated in 96-well plates with $24 \mathrm{~h}$ incubation, and then exposed to DOX@PLA@Au-PEG-MnP NPs (with various concentrations) pretreated with or without NIR light (1.5 $\mathrm{W}, 10 \mathrm{~min})$ respectively. Then, cell viability was measured by standard MTT method after further $48 \mathrm{~h}$ incubation.

\section{Animal experiment}

The animal experiment was investigated on HT-29 tumor-bearing nude mice. When the tumor volume reached $\sim 100 \mathrm{~mm}^{3}$, nude mice were randomly divided in to four groups $(\mathrm{n}=7)$ and were intravenously injected with $200 \mu \mathrm{L}$ of PBS, free DOX, PLA@Au-PEG-MnP NPs and DOX@PLA@AuPEG-MnP NPs, respectively. At $24 \mathrm{~h}$ post-injection, tumors in nude mice were irradiated by continuous-wave diode NIR laser at $1.5 \mathrm{~W} / \mathrm{cm}^{2}$ for $10 \mathrm{~min}$. The temperature of the tumor was recorded by a thermometer probe during the irradiation period. The tumor sizes were measured by a caliper every three days after photothermal treatment and calculated according to the formulation: The tumor volume $=$ (tumor length) $\times$ (tumor width) $2 / 2$. The distribution of DOX@PLA@Au-PEG-MnP NPs in blood, tumor and major organs including heart, liver, spleen, lung and kidney were investigated. All the animal experiments were approved by institutional animal use committee and carried out ethically and humanely.

\section{MRI procedure}

The relaxation times of DOX@PLA@ Au-PEG-MnP NPs at different concentration were measured at $0.5 \mathrm{~T}$ with NMI20 Analyst (Shanghai Niumag Corporation, China). Relaxivity $\mathrm{r}_{1}$ was obtained from the slopes of the relaxation time $\left(\mathrm{T}_{1}\right)$ vs the concentration of $\mathrm{Mn}^{3+}$. $\mathrm{T}_{1}$-weighted images of DOX@PLA@Au-PEG-MnP NPs at different concentrations in pure water were also acquired at $0.5 \mathrm{~T}$ with NMI20 Analyst using a spin-echo pulse sequence with pulse repetition time $\mathrm{D}_{0}=300 \mathrm{~ms}$. To investigate the in vivo MRI potential, HT-29 tumor-bearing mice were intravenously injected with DOX@PLA@Au-PEG-MnP NPs $(100 \mu \mathrm{L}, 8$ mg/mL) and imaged with Pharmascan 70/16 US In-vivo MRI system (Bruker, $7.0 \mathrm{~T}, \mathrm{TR}=1000 \mathrm{~ms}, \mathrm{TE}=9 \mathrm{~ms}$ ) at different time intervals.

\section{Result and discussion}

\section{Preparation and characterization of DOX@PLA@Au-PEG-MnP NPs}

DOX was loaded into PLA nanoparticles through a nanoemulsion method [42]. To get the maximum entrapment efficiency and relative high drug loading content, the weight ratio (DOX: PLA) of 1:10 was chosen [42]. TEM image (Fig 2A) revealed that as-prepared DOX@PLA NPs possessed a spherical morphology and smooth surface. The dynamic light scattering data showed that DOX@PLA NPs have a narrow size distribution of $98.6 \pm 8.5 \mathrm{~nm}$ (Supplementary Material: Table S1), in agreement with TEM measurement. Owing to the negative surface charge of $-14.87 \pm 0.73 \mathrm{mV}$, DOX@PLA NPs could easily adsorb positively charged $\mathrm{PAH}$ for subsequent attachment of negative charged citrate-stabilized Au NPs with a diameter of about $3 \mathrm{~nm}$ and a absorption peak at 520nm (Supplementary Material: Table S1; Fig S4). The densely distributed dark spots seen in the TEM micrograph revealed the successful deposition of Au NPs onto the surface of DOX@PLA NPs (Fig 2B), which made the plasmon resonance around $500 \sim 600 \mathrm{~nm}$ increase to form a peak (Fig 2E). The attached gold NPs were able to nucleate the growth of a gold coating around the microcapsule surface through seeding procedure by further reduction of $\mathrm{HAuCl}_{4} \bullet 4 \mathrm{H}_{2} \mathrm{O}$ to bulk metal [43]. As gold nanoparticles grew large enough to aggregate, a dense gold nanoshells around the surface of DOX@PLA NPs were achieved. The obtained DOX@PLA@Au NPs turned to be rough in the border and looked to be much more compact (Fig 2C). Compared with DOX@PLA NPs, the DOX@PLA@Au NPs had an increased size distribution of $114.7 \pm 6.8$ $\mathrm{nm}$ (Supplementary Material: Table S1), indicating 
gold shell thickness of about $8 \mathrm{~nm}$, which led to a new broad peak ranging from 600 to $900 \mathrm{~nm}$ (Fig 2E). The red shift and broaden of plasmon resonance peak of gold species could be attributed to the wider size distribution and aggregation of the gold nanoparticles on the capsule surface [44]. The broad absorbance between 600 and 900 nm ensured that DOX@PLA@Au NPs could operate as a photo-absorbing agent for NIR light mediated PTT, where there is minimum light absorption in tissues.

After covalent attachment of $\mathrm{MnP}$ to the surface DOX@PLA@Au NPs, no obvious change was seen in the morphology of the obtained DOX@PLA@ Au-PEG-MnP NPs (Fig 2D). But, the zeta potential was converted to be $-31.4 \pm 3.82 \mathrm{mV}$ and the mean diameter increased to $123.6 \pm 9.4 \mathrm{~nm}$ (Supplementary Material: Table S1) ascribable to the introduction of the strong negatively charged sulfonate groups of $\mathrm{MnP}$ and the high molecular weight of the PEG spacers. As shown in Fig 2E, several narrow absorption peaks ranged from $400 \mathrm{~nm}$ to $500 \mathrm{~nm}$ (characteristic absorption peaks of $\mathrm{MnP}$ showed in Supplementary Material: Fig S5) provided an additional evidence for successful linkage of $\mathrm{MnP}$ to the surface DOX@PLA@Au NPs using PEG as spacers. Through ICP measurement, the $\mathrm{Au}$ and $\mathrm{Mn}$ content in DOX@PLA@Au-PEG-MnP NPs were evaluated to be
$47.28 \pm 5.33$ wt. $\%$ and $0.74 \pm 0.21$ wt. $\%$, respectively.

\section{Photothermal effect of DOX@PLA@Au-PEG- MnP NPs}

The photothermal effect of DOX@PLA@ Au-PEG-MnP NPs was evaluated under the irradiation of NIR light (808 nm, $2 \mathrm{~W}$ ) for $10 \mathrm{~min}$ in RPMI 1640 as well as in water. As shown in Fig 3A and 3B, the temperature collected by a digital thermometer every $10 \mathrm{~s}$ of samples under irradiation. It was found that the temperature rose with increasing exposure time and concentration of DOX@PLA@Au-PEG-MnP NPs solution. At the concentration of 0.2 and 0.4 $\mathrm{mg} / \mathrm{mL}$, the temperature elevations were $19^{\circ} \mathrm{C}$ and $13^{\circ} \mathrm{C}$ in water medium (Fig $3 \mathrm{~A}$ ), while the temperature elevations were $21^{\circ} \mathrm{C}$ and $13{ }^{\circ} \mathrm{C}$ in RPMI 1640 medium (Fig 3B). In contrast, no significant temperature elevation was observed when water or RPMI 1640 was exposed to NIR light, verifying the excellent photothermal efficiency of DOX@PLA@Au-PEG-MnP NPs. At the initial temperature of about $27^{\circ} \mathrm{C}$ and concentration of $0.4 \mathrm{mg} / \mathrm{mL}$, the solutions can be easily heated up to above $45^{\circ} \mathrm{C}$, which can efficiently kill cancer cells at this level of temperature [8]. The data suggested that the DOX@PLA@Au-PEG-MnP NPs could operate an efficient photo-absorber for PTT of cancer.
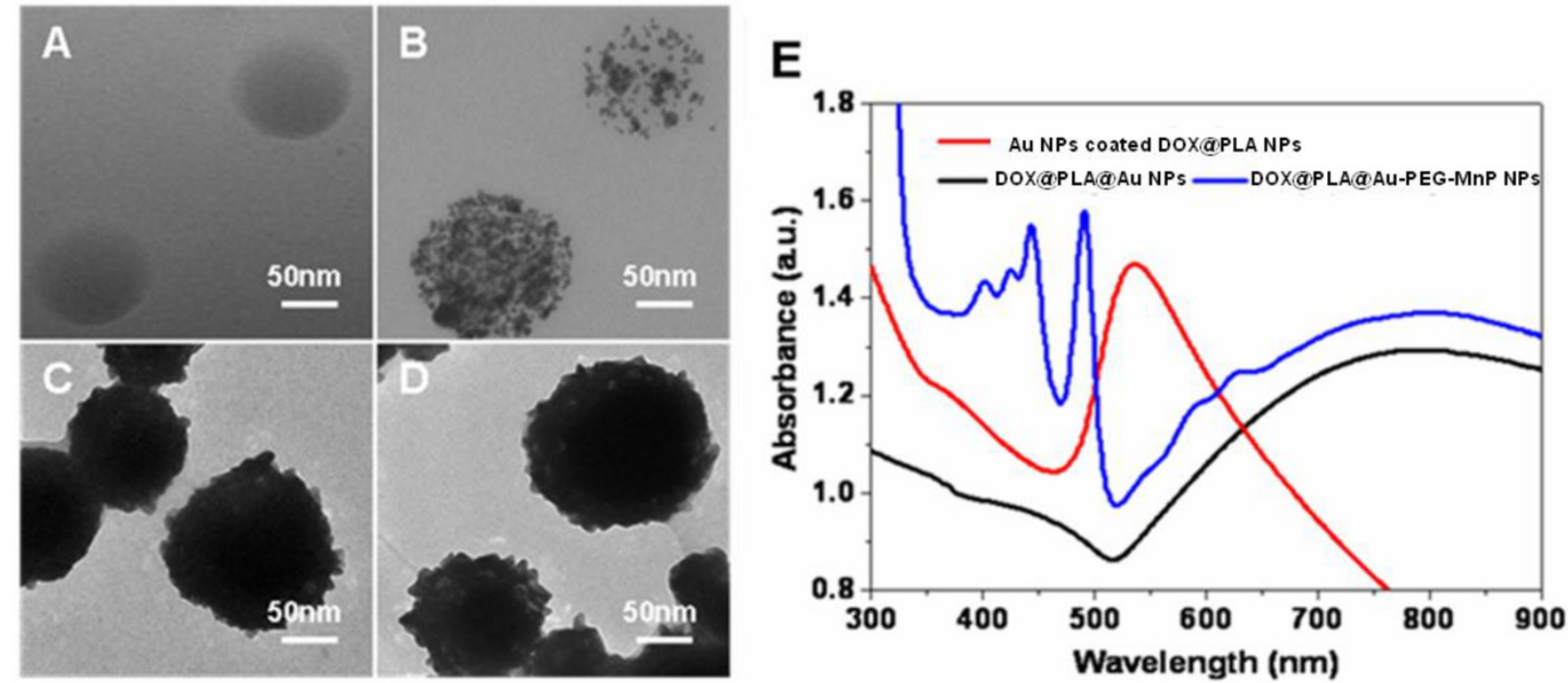

Figure 2. (A) - (D) TEM micrographs of the nanoparticles at different fabrication stages: (A) DOX@PLA NPs, (B) Au NPs coated DOX@PLA NPs, (C) DOX@PLA@Au NPs, (D) DOX@PLA@Au-PEG-MnP NPs. (E) UV/vis absorption spectra of the nanoparticles of Au NPs coated DOX@PLA, DOX@PLA@Au and DOX@PLA@Au-PEG-MnP in aqueous solution. 

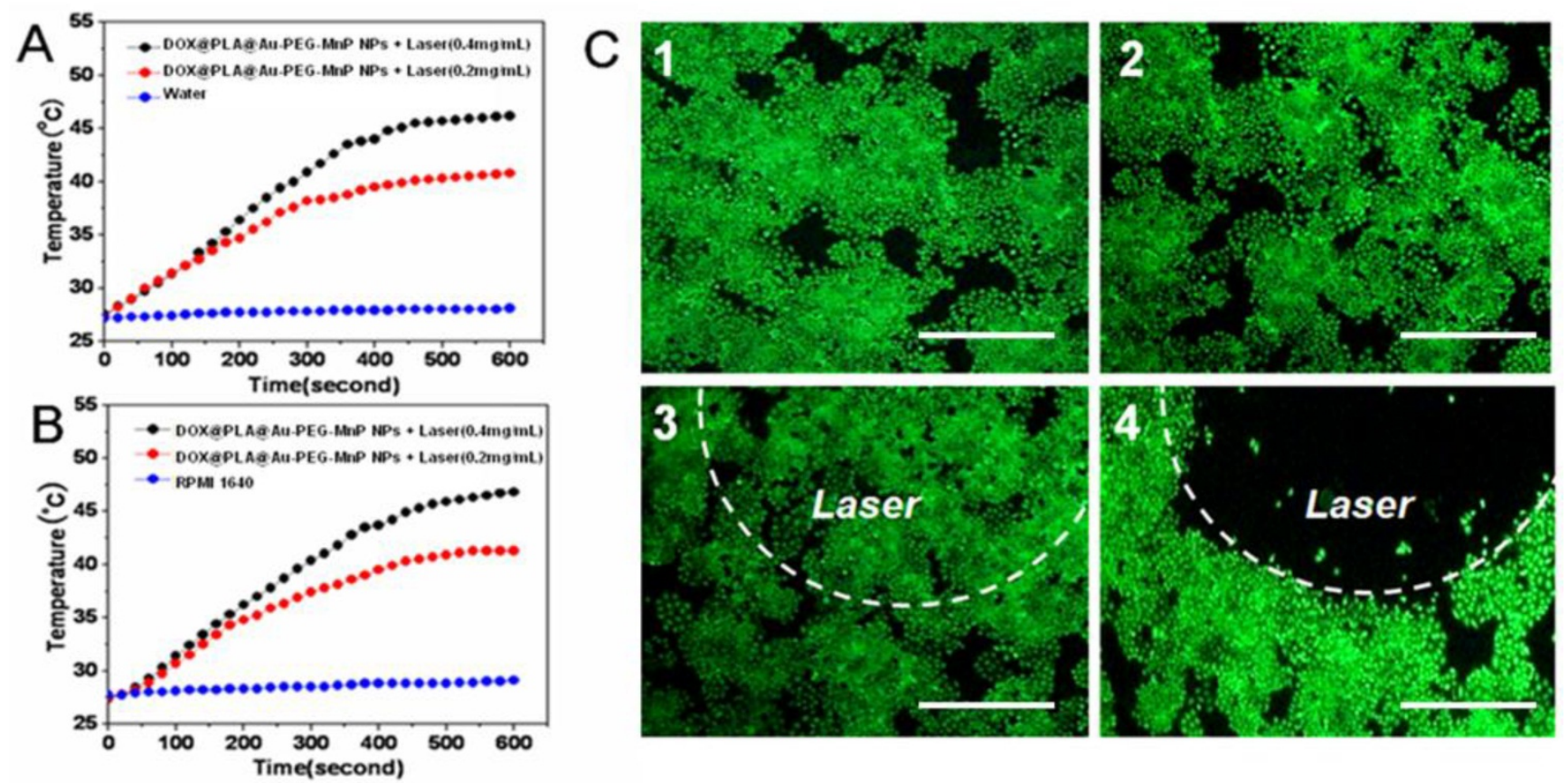

Figure 3. Temperature elevations of DOX@PLA@Au-PEG-MnP NPs at different concentrations under NIR laser irradiation (808 nm, 2 W): (A) in water; (B) in RPMI 1640. (C) Fluorescence microscopy images of HT-29 cells with different treatments stained with calcein AM: (I) no agent and no laser irradiation; (2) PLA@Au-PEG-MnP NPs only; (3) laser irradiation only; (4) with both PLA@Au-PEG-MnP NPs and laser irradiation. (Scale bars: 300 um).

To visualize the solo photohyperthermic cytotoxicity, HT-29 cells were incubated with PLA@Au-PEG-MnP NPs with no DOX for $2 \mathrm{~h}$, followed by illumination with an NIR laser $(808 \mathrm{~nm}, 1.5$ $\mathrm{W} / \mathrm{cm}^{2}$ ) for $10 \mathrm{~min}$. Upon the exposure of the cancer cells to higher temperatures, normal cellular growth and proliferation could be inhibited by denaturing intracellular proteins [45]. After treatment with variable combination of agents and lasers, cell viability was assessed by fluorescent cell staining with non-fluorescent cell permeable dye calcein AM, which can turn into strongly green fluorescent calcein after hydrolysis by intracellular esterases in live cells [46]. Under inverted fluorescence microscope (Fig 3C), a dark region was seen in combination of the PLA@Au-PEG-MnP NPs and laser irradiation due to NIR laser-induced hyperthermic effect on cancer cells (Fig 3C4). Cancer cells outside of the illumination spot showed green fluorescence, suggesting the survival cancer cells. On the contrary, all the other three samples exhibited vivid green color in the entire well (Fig $\left.3 \mathrm{C}_{1-3}\right)$. It demonstrated that the exposure of cancer cells to either PLA@Au-PEG-MnP NPs or high intensity NIR laser alone could not efficiently kill cancer cells. The dark region in Fig $3 \mathrm{C}_{4}$ matched the laser irradiation area very well, revealing that the agent with Au nanoshell could induce cancer cells to death through photohyperthermic effect only in combination of the irradiation of NIR lasers.

\section{Drug release}

The loading content of DOX in DOX@PLA@Au-PEG-MnP NPs was evaluated to be $3.57 \pm 0.61 \%$. The $T g$ value of the inner PLA matrix of DOX@PLA NPs was $53.1^{\circ} \mathrm{C}$ (Supplementary Material: Fig S6) by differential scanning calorimetry (DSC) using a TGA/SDTA851e Instruments (Mettler-Toledo, Switherland). Fig 4A shows the accumulative DOX release profile. A significant difference in the DOX release was observed between DOX@PLA NPs and DOX@PLA@Au-PEG-MnP NPs before and after NIR laser irradiation. In physiologic temperature, only about $11 \%$ of DOX was released from the DOX@PLA@Au-PEG-MnP NPs within 24h, much slower than DOX@PLA NPs, which released about $29 \%$ of DOX within $240 \mathrm{~h}$ at $37^{\circ} \mathrm{C}$. The slower release rate for DOX@PLA@Au-PEG-MnP NPs was attributed to their Au nanoshell, which block the drug release channels. Actually, the formed Au shell was incomplete, which was the reason for the drug release without laser irradiation. In contrast, nearly $39 \%$ of DOX was released from DOX@PLA@Au-PEG-MnP NPs within $24 \mathrm{~h}$ upon one-time irradiation of NIR laser $(808 \mathrm{~nm}$ and $2 \mathrm{~W}$ ) for $10 \mathrm{~min}$, much faster than DOX@PLA NPs. It suggested that the photothermal effect of Au nanoshell can be utilized to trigger DOX release from the inner PLA matrix of DOX@PLA@Au-PEG-MnP NPs.

To further evaluate the NIR light triggered DOX release, DOX@PLA@Au-PEG-MnP NPs were irradi- 
ated repeatedly over a period of $10 \mathrm{~min}$, followed by 50 min intervals with the laser turned off. A rapid DOX release was achieved upon NIR laser irradiation and the drug release rate slowed down when the laser was switched off. After the first irradiation for $10 \mathrm{~min}$, the percentage of released DOX increased from $0 \%$ to $10.6 \%$. After three cycles of laser on/off, $37.9 \%$ of DOX was released from DOX@PLA@Au-PEG-MnP NPs within $180 \mathrm{~min}$, significantly higher than that without NIR irradiation (8.8\%). It was about 4 -fold greater than that without laser irradiation. It was found that the DOX release amount after each irradiation decreased from the first cycle to the third cycle. It would result from the decreased coverage of gold nanoshells due to the melting effect of gold nanostructures [47]. All the results successfully demonstrated a stepwise triggered release based on NIR exposure using DOX@PLA@Au-PEG-MnP NPs, which was likely attributed to the high temperature (above the Tg of PLA matrix) caused by the autologous photohyperthermia effect of the Au nanoshell under the irradiation of NIR laser.

\section{Colloidal stability and circulation profile of DOX@PLA@Au-PEG-MnP NPs}

It has been demonstrated that PEG modified nanoparticles show significantly improved colloidal stability and prolonged circulation time in vivo [48, 49]. For this purpose PEG chains were introduced onto the surface of DOX@PLA@Au for conjugating $\mathrm{MnP}$. Upon exposure to PBS $(10 \mathrm{mM}, \mathrm{pH} 7.4)$ at $37^{\circ} \mathrm{C}$, no obvious change in the mean diameter of DOX@PLA@Au-PEG-MnP NPs within one week, suggesting their excellent colloidal stability (Fig 5A). In contrast, DOX@PLA@Au with no PEG showed significantly increased size distribution, indicating the aggregation of the NPs occurred.
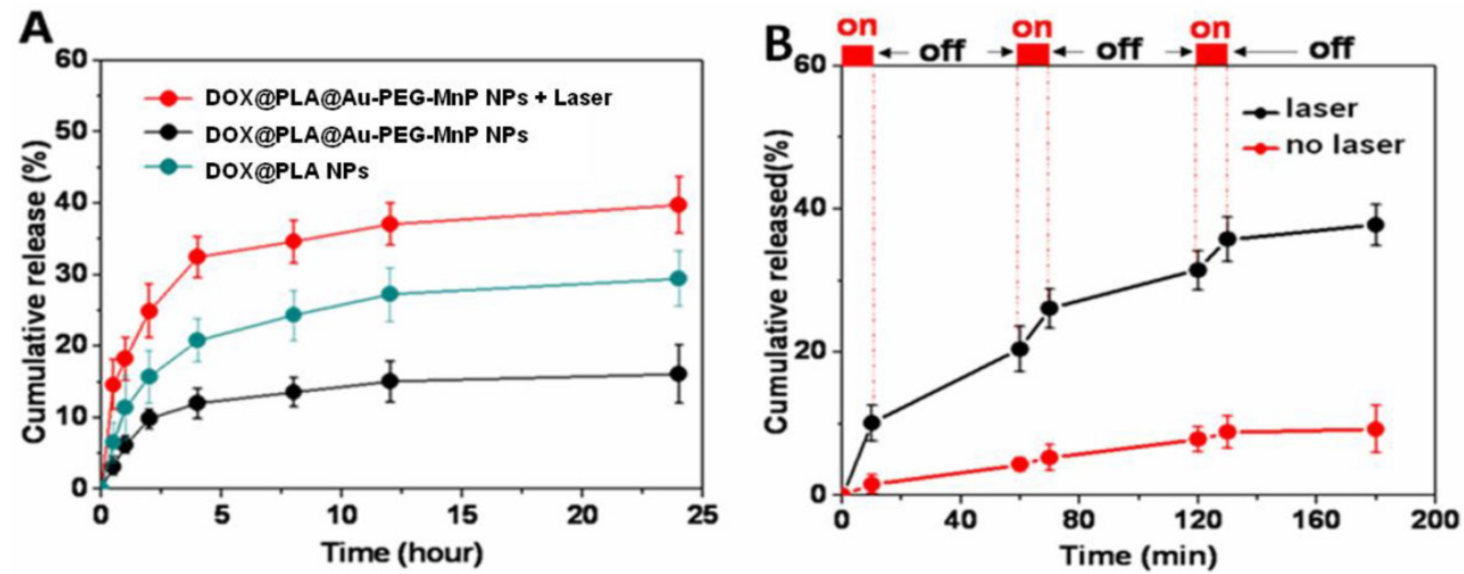

Figure 4. (A) DOX release profiles from DOX@PLA NPs and DOX@PLA@Au-PEG-MnP NPs without or with NIR irradiation (I0 min, $808 \mathrm{~nm}, 2 \mathrm{~W})$ at $37^{\circ} \mathrm{C}$. (B) DOX release profile from DOX@PLA@Au-PEG-MnP NPs with three cycles of laser on/off. Control samples were not irradiated over the whole period. All release studies were performed in triplicate.
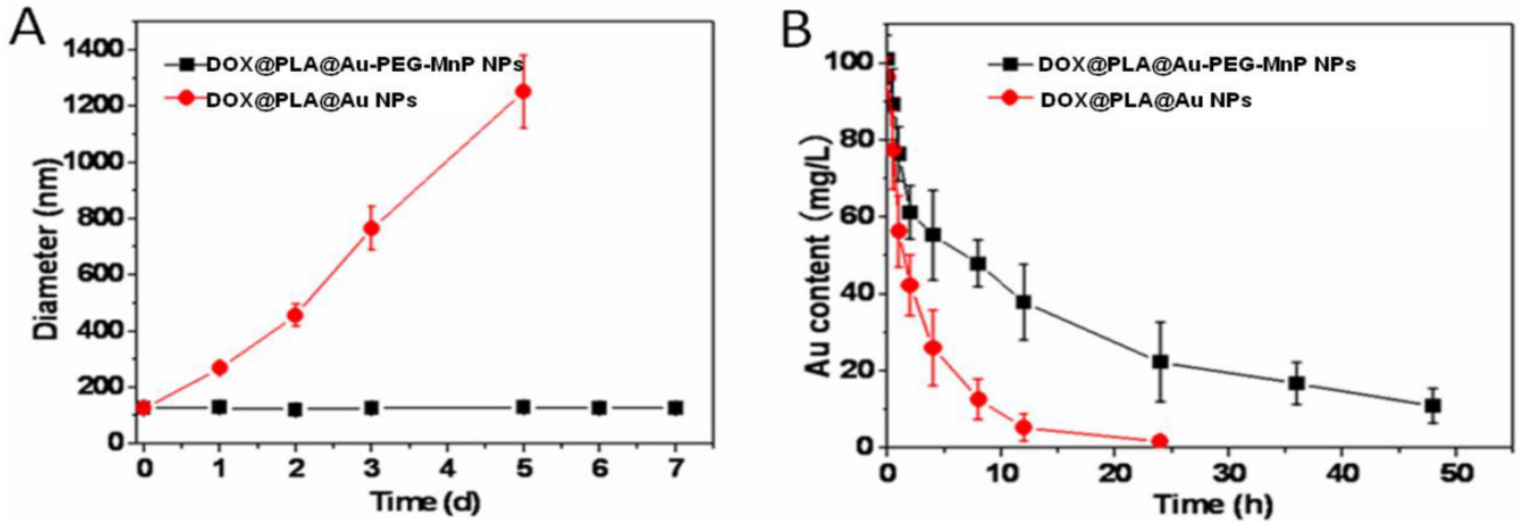

Figure 5. (A) The changes of size distributions of DOX@PLA@Au-PEG-MnP NPs and DOX@PLA@Au NPs in PBS (I0 mM, pH 7.4) at $37^{\circ} \mathrm{C} .(\mathrm{B})$ Concentration-time profiles of Au element in plasma of Wistar rats after intravenous injection of DOX@PLA@Au-PEG-MnP NPs and DOX@PLA@Au $\mathrm{NPs}$ at an Au dosage of $30 \mathrm{mg} / \mathrm{kg}$. Error bars were based on standard deviations of 3 rats per group. 
The blood circulation dynamics of DOX@PLA@Au-PEG-MnP NPs was investigated in comparison with DOX@PLA@Au. Wistar rats were intravenously administrated with the agent at an $\mathrm{Au}$ dosage of $30 \mathrm{mg} / \mathrm{kg}$. The circulation profile of the agent was evaluated by measuring the Au content in blood over the course of $48 \mathrm{~h}$ via ICP measurement. Parameters including elimination half-life $\left(\mathrm{T}_{1 / 2}\right)$, mean residence time (MRT) and area under the plasma concentration-time curve from zero to time infinity $\left(\mathrm{AUC}_{0-\infty}\right)$ were evaluated using the KineticaTM software package (version 5.0, Thermo Fisher Scientific Inc., MA, USA). As seen in Fig 5B, DOX@PLA@Au-PEG-MnP NPs displayed a significant longer blood circulation time than DOX@PLA@Au. The Au content of the later decreased to $48.6 \%$ at $6 \mathrm{~h}$ and almost disappeared at 24 $\mathrm{h}$ in blood circulation, exhibiting rapid clearance kinetics. On the contrary, the Au content of the former remained to be $87.7 \%$ at $24 \mathrm{~h}$, showing dramatically prolonged and slow clearance kinetics. $\mathrm{T}_{1 / 2}, \mathrm{MRT}$ and $\mathrm{AUC}_{0-\infty}$ of Au element were calculated to be $4.5 \mathrm{~h}, 5.76$ $\mathrm{h}$ and $347.61 \mathrm{hmg} / \mathrm{L}$ for DOX@PLA@Au, respectively. In contrast, these values were significantly increased to be $39.78 \mathrm{~h}, 61.46 \mathrm{~h}$ and $2644.87 \mathrm{~h} \mathrm{mg} / \mathrm{L}$ for DOX@PLA@Au-PEG-MnP NPs, respectively. Thus, it provided evidence that DOX@PLA@Au-PEG-MnP NPs can maintain a long circulation due to the introduction of PEG chains.

\section{Cytotoxicity}

To further investigate the combined effects of photothermal cytotoxicity and chemotherapy of DOX@PLA@Au-PEG-MnP NPs, we determined cell viability for HT-29 cells after incubation with the DOX loaded (or free) agents of different concentrations with or without laser irradiation by MTT assay. Fig $6 \mathrm{~A}$ showed that no cytotoxicity was observed when HT-29 cells were incubated with PLA@Au-PEG-MnP containing no DOX over $48 \mathrm{~h}$ even at the highest incubated concentration of $1.0 \mathrm{mg} / \mathrm{mL}$ without NIR light exposure. For comparative study the agent's cytotoxicities, HT-29 cells were incubated with free DOX, PLA@Au-PEG-MnP, and DOX@PLA@AuPEG-MnP at various concentrations for $24 \mathrm{~h}$ in combination of the irradiation of NIR light at $1.5 \mathrm{~W} / \mathrm{cm}^{2}$ in initial $10 \mathrm{~min}$ of the $24 \mathrm{~h}$ time period. The free DOX group had equivalent concentration of DOX to the DOX@PLA@Au-PEG-MnP group, and the PLA@Au-PEG-MnP group had an equivalent $\mathrm{Au}$ dosage to the DOX@PLA@Au-PEG-MnP group. As seen in Fig 6B, all three therapies showed an increasing cytotoxicity against HT-29 cells in a dose-dependent manner. At the highest dose, cell viability decreased to $45 \%$ for free DOX $(9 \mu \mathrm{g} / \mathrm{mL}$ of DOX), $38 \%$ for PLA@Au-PEG-MnP $(125 \mu \mathrm{g} / \mathrm{mL}$ of $\mathrm{Au}), 13 \%$ for DOX@PLA@Au-PEG-MnP $(125 \mu \mathrm{g} / \mathrm{mL}$ of $\mathrm{Au}, 9 \mu \mathrm{g} / \mathrm{mL}$ of DOX). These results revealed that the combination of chemotherapy and photothermal therapy through DOX@PLA@Au-PEG-MnP significantly increased the likelihood of cell killing, and potentially overcame the resistance to chemotherapeutic agents, making it a promising approach for cancer therapy.
A
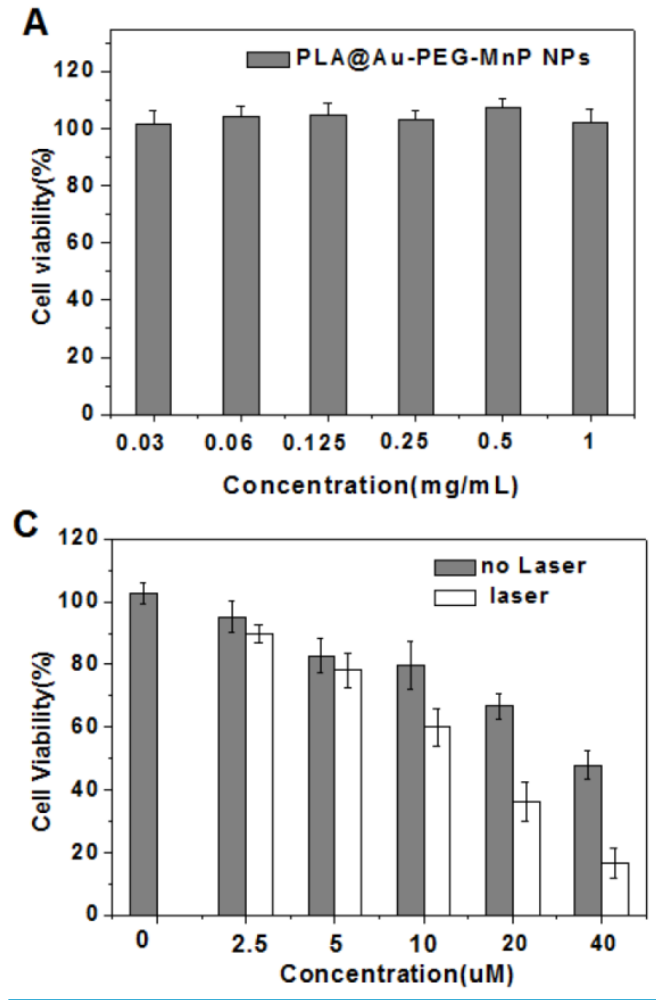

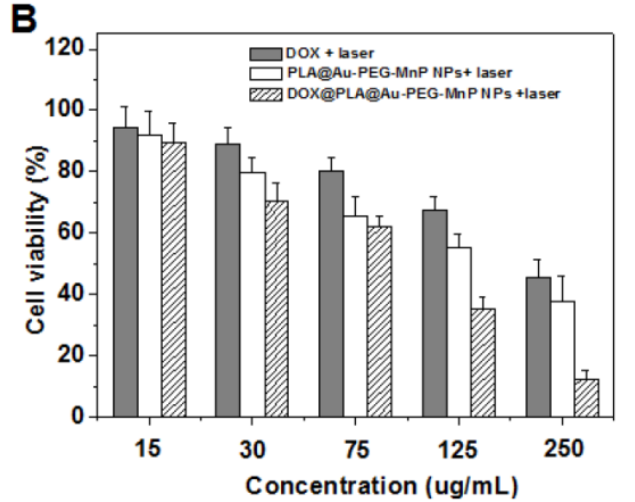

D

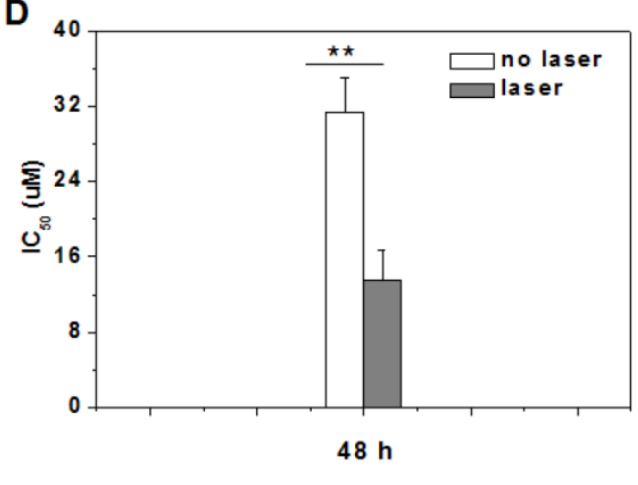

Figure 6. Cell viability of HT-29 cells determined by MTT method after incubation with: (A) PLA@Au-PEG-MnP NPs (drug free carrier) of different concentrations for 48h; (B) DOX, PLA@Au-PEG-MnP NPs and DOX@PLA@Au-PEG-MnP NPs of different concentrations for $24 \mathrm{~h}$ followed by treatment with NIR laser $(808 \mathrm{~nm}, \quad 1.5$ $\mathrm{W} / \mathrm{cm}^{2}$ ) in initial $10 \mathrm{~min}$ of the 24 h time period; (C) DOX@PLA@Au-PEG-MnP NPs of different concentrations for $48 \mathrm{~h}$ with and without the pretreatment of NIR laser irradiation; (D) The $I C_{50}$ values of DOX@PLA@Au-PEG-MnP NPs with and without the pretreatment of NIR laser irradiation for $48 \mathrm{~h}$ incubation. 
As shown in Fig 6C, without laser irradiation, HT-29 cells treated with DOX@PLA@Au-PEG-MnP NPs of various concentrations showed relatively lower cell viability compared to control group. In addition, the cell viability decreased with increasing the NPs concentrations. It suggested the effect of DOX acting as chemotherapeutic drug. When exerting the NIR laser irradiation, the decrease in the cell viability became more remarkable. The $\mathrm{IC}_{50}$ values were evaluated to be $14.1 \mu \mathrm{M}$ and $30.8 \mu \mathrm{M}$ for DOX@PLA@Au-PEG-MnP NPs with and without NIR laser irradiation, respectively (Fig 6 D). The enhanced cytotoxicity was attributed to the increased DOX concentration in the inner or surrounding microenvironment of cancer cells, which caused by the triggered release of DOX from DOX@PLA@AuPEG-MnP NPs under the irradiation of NIR laser. Therefore, DOX@PLA@Au-PEG-MnP NPs could significantly improve the therapeutic accuracy of DOX through the remote control by NIR laser.

\section{MRI imaging}

Mn-porphyrins, a serious of potential MRI contrast agents, have been reported as promising substitutes for $\mathrm{Gd}^{+3}$ based complexes. Owing to the existence of attractive force between water soluble porphyrins and the surrounding water molecules, the rigid porphyrin structure could potentially modulate the internuclear distance between the paramagnetic metal center and the hydrogen atoms in the surrounding water molecules, thus Mn-porphyrins usu- ally exhibited high $\mathrm{r}_{1}$ relaxivity [35]. Fig 7A indicated that the $\mathrm{T}_{1}$ relaxation time increases as the concentrations of $\mathrm{Mn}^{3+}$ increasing and the trend is well fit by a linear line within the analyzed range of $\mathrm{Mn}^{3+}$ concentrations for both free $\mathrm{MnP}$ and DOX@PLA@Au-PEG-MnP NPs. At the magnetic field strength of $0.5 \mathrm{~T}$, the $\mathrm{r}_{1}$ relaxivity of free $\mathrm{MnP}$ were measured as $6.70 \mathrm{mM}^{-1} \mathrm{~s}^{-1}$, higher than that of clinical approved Gd-DTPA $\left(4.5 \mathrm{mM}^{-1} \mathrm{~s}^{-1}\right)$ at the same magnetic field strength[50]. More excitingly, after the covalent linkage of $\mathrm{MnP}$ onto the surface of DOX@PLA@Au through PEG chains, this $\mathrm{r}_{1}$ value significantly increased to $22.18 \mathrm{mM}^{-1} \mathrm{~s}^{-1}$, which was more than three times as high as that of free $\mathrm{MnP}$ (Fig $7 \mathrm{~A})$. It is has been reported that the $\mathrm{r}_{1}$ values of various paramagnetic metal complexes could be highly enhanced by grafting them onto solid supports due to the reduction of tumbling rate of those paramagnetic metal complexes and the effective interaction between water and the paramagnetic metal complexes [51]. Hence, the $\mathrm{r}_{1}$ relaxivity of DOX@PLA@Au-PEG-MnP NPs was strongly enhanced due to grafting MnPonto the $\mathrm{Au}$ nanoshell surface and the introduction PEG spacers. In addition, $\mathrm{T}_{1}$ weighted images of phantoms containing aqueous dispersions of DOX@PLA@Au-PEG-MnP NPs showed that the signal intensity of MRI increased with the increase of the $\mathrm{Mn}^{3+}$ concentrations (Fig 7B). It further confirmed that DOX@PLA@Au-PEG-MnP NPs could operate as an excellent positive MRI contrast agent.
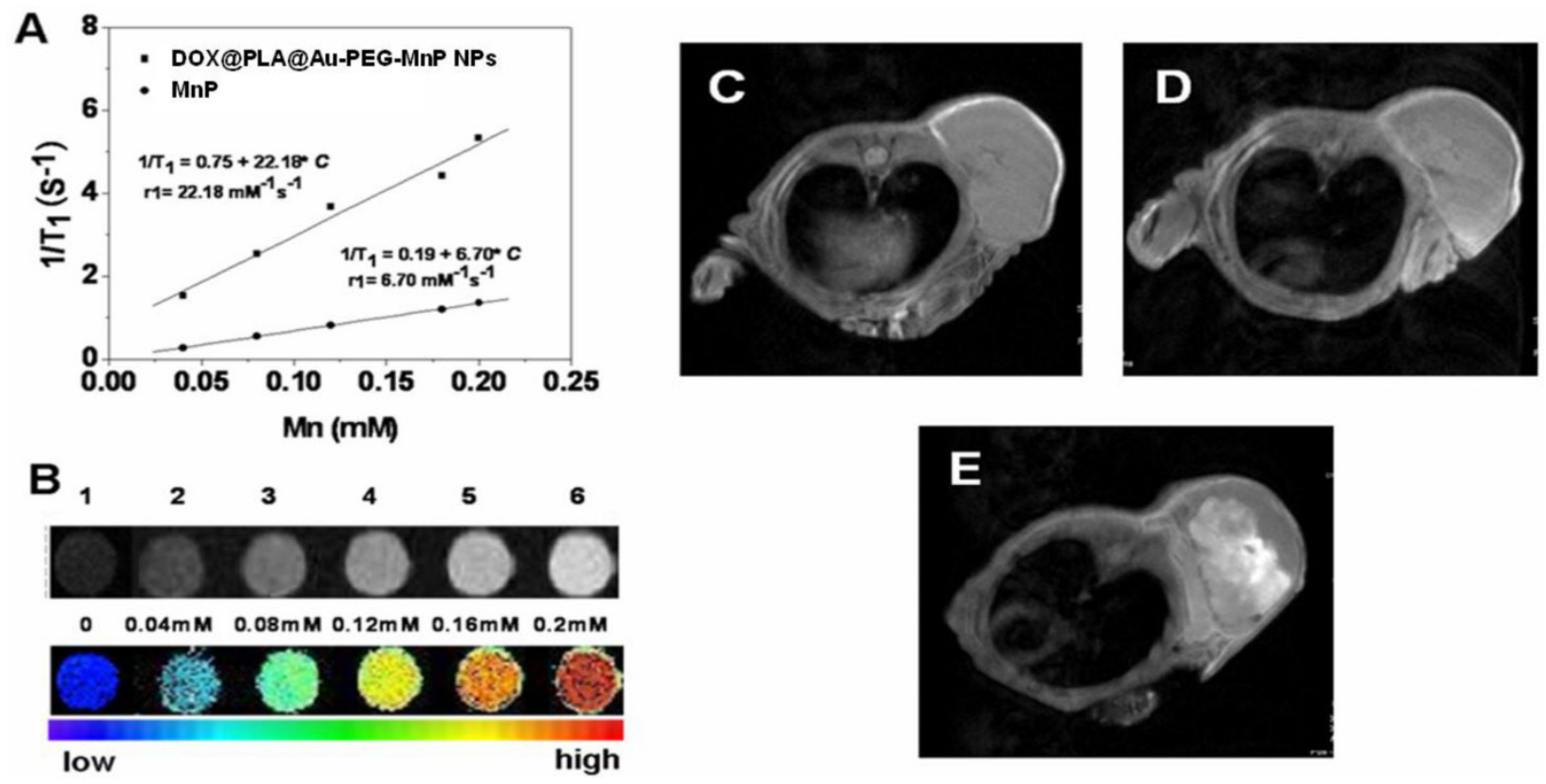

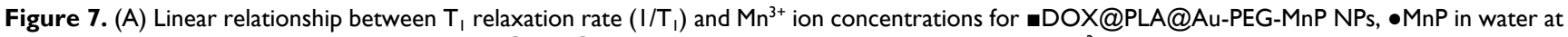
$0.5 \mathrm{~T}$ and $37^{\circ} \mathrm{C}$, (B) $\mathrm{T}_{1}$-weighted images of DOX@PLA@Au-PEG-MnP NPs with increasing amount of $\mathrm{Mn}^{3+}$ at $0.5 \mathrm{~T}, 37^{\circ} \mathrm{C}, \mathrm{D}_{0}=300 \mathrm{~ms}$. The in vivo MRI images of DOX@PLA@Au-PEG-MnP NPs (100 $\mu$ L, 8 mg/mL): (C) before injection, (D) 30 min after injection, (E) 24 h after injection. 
In vivo MRI potential of DOX@PLA@AuPEG-MnP NPs was evaluated on HT-29 tumor-bearing nude mice. The tumors were imaged with the Pharmascan 70/16 US In-vivo MRI system at 7.0 $\mathrm{T}$ before and after intravenous single injection of the agent $(100 \mu \mathrm{L}, 8 \mathrm{mg} / \mathrm{mL})$. As shown in Fig 7C-E, $\mathrm{T}_{1}$-weighted MRI was able to capture the detailed structure of the tumor after administration of the NPs. Compared with the homogeneous and slight dark image before injection (Fig 7C); the signal enhancement in tumor region was gradually obvious as the time increased. There were obvious bright dots in the tumor area after $0.5 \mathrm{~h}$ and $24 \mathrm{~h}$ post-injection of nanoparticles, indicating an inhomogeneous distribution of the contrast agent within the tumor (Fig 7D and 7E). In addition, after $24 \mathrm{~h}$ injection, the whole tumor area was becoming much brighter than that before administration, suggesting large amount of DOX@PLA@Au-PEG-MnP NPs were accumulating in the tumor area. The tumor sites exhibited obvious increase in $\mathrm{T}_{1}$-weighted $\mathrm{MR}$ intensity compared with that before injection, indicating that the DOX@PLA@Au-PEG-MnP NPs remain in the tumor sites as long as $24 \mathrm{~h}$ to provide adequate time for the following treatment. The passive targeting and high MRI contrast ability of MnP-DOX GPNPs are favorable for accurate cancer diagnosing and locating the tumor site to guide the external NIR laser irradiation
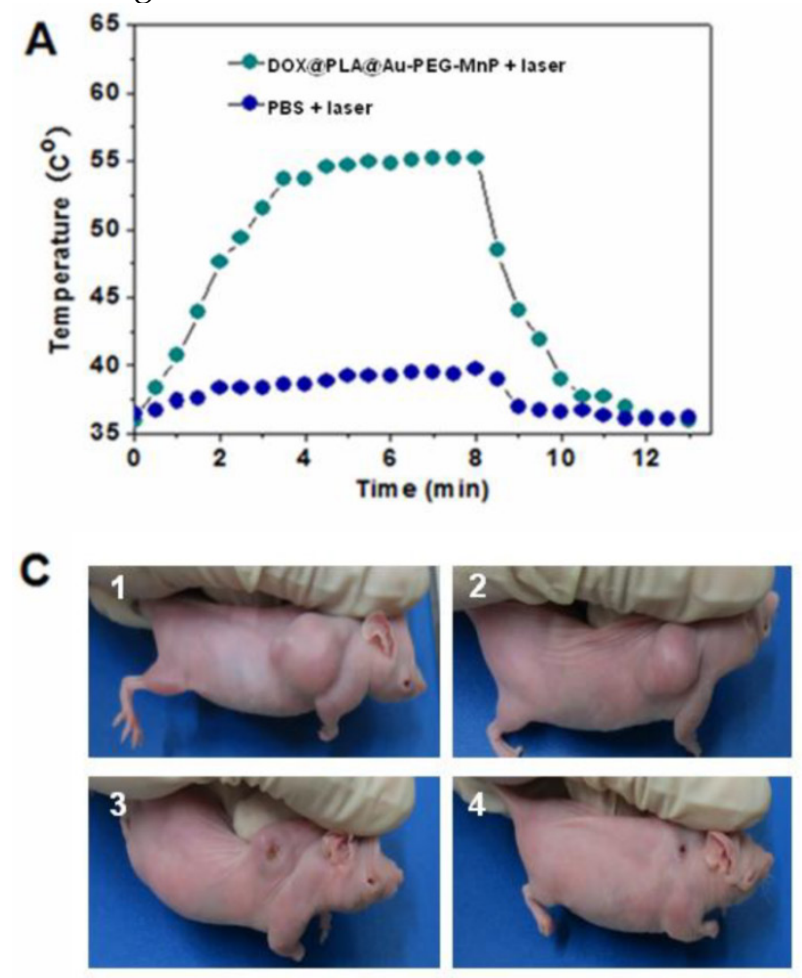

for photothermal ablation of tumors without damaging the surrounding healthy tissues.

\section{In vivo therapeutic investigation}

The antitumor efficiency of the combined photothermal-chemotherapy using DOX@PLA@AuPEG-MnP NPs was investigated on HT-29 tumor-bearing nude mice. When tumor size reached approximately $100 \mathrm{~mm}^{3}$, PBS, free DOX, PLA@AuPEG-MnP NPs and DOX@PLA@Au-PEG-MnP NPs solutions were administered by intravenous injection, respectively. The free DOX group used an equivalent DOX concentration to the DOX@PLA@Au-PEG-MnP group $(0.1 \mu \mathrm{mol})$, and the used Au dosage for the PLA@Au-PEG-MnP group was equivalent to the DOX@PLA@Au-PEG-MnP group (1.6 mg). Upon exposure to the $808 \mathrm{~nm}$ laser with a low power density of $1.5 \mathrm{~W} / \mathrm{cm}^{2}$ for $8 \mathrm{~min}$, the temperature in the tumor areas of mice from both PLA@Au-PEG-MnP and DOX@PLA@Au-PEG-MnP treated groups could rapidly increased because of the high photothermal efficiency of their Au nanoshells. As shown in Fig 8A, the average temperature of tumor tissue treated with DOX@PLA@Au-PEG-MnP increased from $36.5{ }^{\circ} \mathrm{C}$ to $57.3{ }^{\circ} \mathrm{C}$ during $8 \mathrm{~min}$ irradiation, which was high enough to kill tumors in vivo. In contrast, the temperature in the tumor areas from PBS + laser group was not obviously affected after laser irradiation.
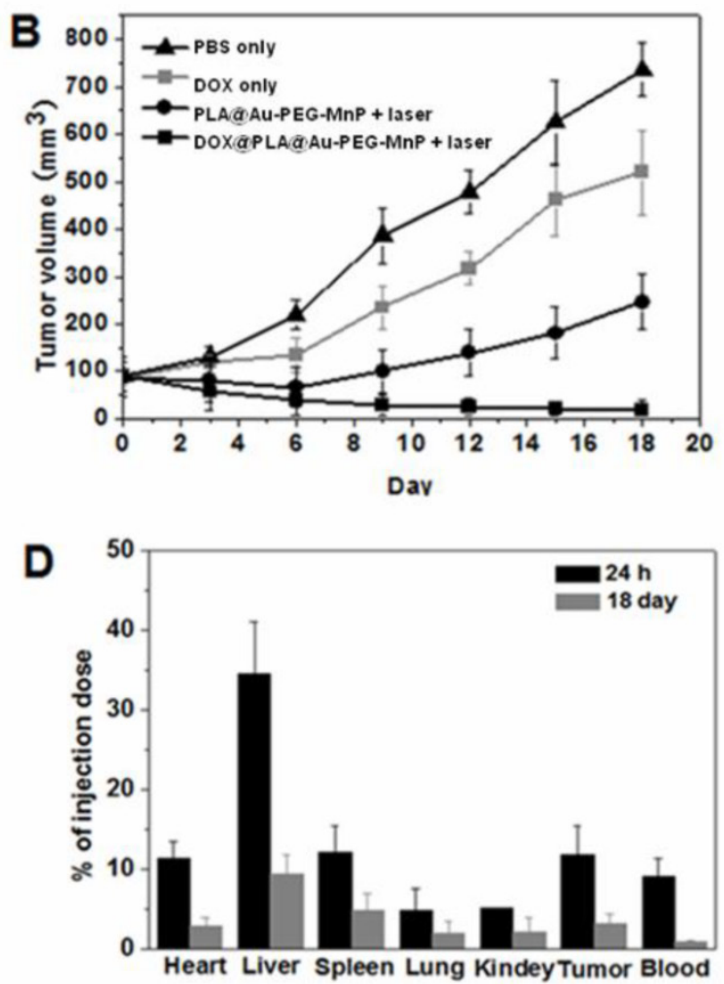

Figure 8. (A) Temperature change curves determined by thermographic camera after treatments of the nude mice tumor with or without DOX@PLA@Au-PEG-MnP NPs upon exposure to the $808 \mathrm{~nm}$ laser at a power density of $\mathrm{I} .5 \mathrm{~W} / \mathrm{cm}^{2}$. (B) The tumor growth curves of different groups of mice after various treatments (A PBS only, - DOX only, •PLA@Au-PEG-MnP + laser, =DOX@PLA@Au-PEG-MnP + laser). (C) Representative photographs of tumors in mice at the 18th day post treatment: (I) PBS, (2) DOX, (3) PLA@Au-PEG-MnP + laser, and (4) DOX@PLA@Au-PEG-MnP NPs + laser). (D) The in vivo biodistributions of Au element at 24h and 18th day post intravenous injection the NPs. 
To evaluate the therapeutic outcome of each group, tumor volumes were recorded (Fig 8B). In PBS treated group, tumor volume increased rapidly, from about $100 \mathrm{~mm}^{3}$ to approximately $800 \mathrm{~mm}^{3}$ over 18 days (Fig $8 \mathrm{~B}$ and $8 \mathrm{C}_{1}$ ). On the contrary, different levels of tumor growth inhibition were seen in other three groups. The tumor volume in mice treated only with DOX increased from about $100 \mathrm{~mm}^{3}$ to approximately $500 \mathrm{~mm}^{3}$ over 18 days (Fig $8 \mathrm{~B}$ and $8 \mathrm{C}_{2}$ ), suggesting that the dosage of administered DOX in our study could not significantly reduce the tumor volume due to the short half-life and nonspecific tumorous uptake of free DOX. In the PLA@Au-PEG-MnP + laser group, tumor volume decreased from about $100 \mathrm{~mm}^{3}$ to approximately $60 \mathrm{~mm}^{3}$ until 6 days. After 6 days, however, the tumor began to regrow and had increased to about $250 \mathrm{~mm}^{3}$ by 18 days (Fig $8 \mathrm{~B}$ and $8 \mathrm{C}_{3}$ ), implying that incomplete destruction of tumor cells by the photothermal treatment can induce a recurrence of the tumor. More excitingly, in DOX@PLA@AuPEG-MnP + laser group, the tumor volume decreased gradually from $100 \mathrm{~mm}^{3}$ to $20 \mathrm{~mm}^{3}$ within 18 day after photothermal treatment, leaving black scars at their original sites without the phenomenon of tumor recurrence (Fig 8B and $8 \mathrm{C}_{4}$ ). In addition, histological section of tumors showed that maximum damage was caused by the synergistic treatment (Fig S7) using DOX@PLA@Au-PEG-MnP NPs in combination with NIR laser irradiation. Overall results demonstrated that the combined DOX and photothermal treatment were more cytotoxic than either treatment alone. Photohyperthermia effect would greatly enhance the permeability of tumor vessels and the sensitivity of the tumor cells toward chemotherapeutics, holding the promise of improving drug efficacy. Moreover, photothermal effect may trigger an instant drug release from DOX@PLA@Au-PEG-MnP NPs, leading to high effective drug concentration in the tumor. Furthermore, NIR laser light as a source of hyperthermia is noninvasive and applied extracorporeally, which takes a major advantage over other types of hyperthermia like radiofrequency ablation or microwave ablation, which require interstitial needle or antenna insertion.

The particle tracking in animal studies is vital to the understanding of the efficacy of drug delivery [52]. The amounts of the NPs accumulated in blood and vital organs were quantified by evaluating the $\mathrm{Au}$ content using ICP measurement. Fig $8 \mathrm{D}$ showed that the in vivo distribution of DOX@PLA@Au-PEG-MnP NPs. At $24 \mathrm{~h}$ post-injection, nearly $90 \%$ amount of injected NPs was found in vital organs (including heart, liver, spleen, lung, kidneys and brain), tumor and blood. Approximately $6.3 \%$ amount of injected NPs was found to accumulate in tumor tissue at $24 \mathrm{~h}$ post-injection, providing an opportunity for the combined photothermal-chemotherapy. Because of the enhanced permeation and retention (EPR) effect, DOX@PLA@Au-PEG-MnP NPs could be passively accumulated into tumor [53]. In addition, the introduction of the PEG layer on the surface of the $\mathrm{Au}$ nanoshells contributes to the inhibition from the macrophage recognition at reticuloendothelial system (RES) of liver and spleen due to the good hydration property, resulting in a prolonged circulation time in blood.

It is worth noting that a relative rapid clearance rate of the NPs was observed in Fig 8D, nearly 60\% amount of the NPs was cleared from the body within 18 days. In addition, histological section of vital organs (including heart, liver, spleen, lung and kidneys) stained with hematoxylin and eosin did not show any apparent injury in cellular structures (Supplementary Material: Fig S8). This result indicated the good safety of the therapeutic process using as-prepared NPs.

\section{Conclusion}

A multifunctional nanoparticle of DOX@PLA@ Au-PEG-MnP has been successfully developed by integrating different components, including PLA as biodegradable drug carrier, gold nanoshell as NIR photo-absorber to perform photothermal therapy and trigger an instant drug release, $\mathrm{MnP}$ as $\mathrm{T}_{1}$ contrast agent to enhance MR imaging, and PEG to prolong the circulation time in vivo, into a single agent. Both in vitro and in vivo experiments demonstrated that DOX@PLA@Au-PEG-MnP NPs exhibited a greatly improved longitudinal relaxivity ( $\mathrm{r}_{1}$ value of 22.18 $\mathrm{mM}^{-1} \mathrm{~s}^{-1}$ of $\mathrm{Mn}^{3+}$ ), facilitating to capture the location and detailed structure of the tumor through MRI. Under the irradiation of NIR laser, the composite agent exhibited excellent photothermal therapeutic potential and triggered DOX release, resulting in accurate and synergistic therapeutic effect of cancer in both cellular experiments and tumor-bearing nude mice model. It was found that the combined DOX and photothermal treatment were more cytotoxic than either treatment alone. NIR laser light as a source of hyperthermia is noninvasive and applied extracorporeally, which takes a major advantage over other types of hyperthermia like radiofrequency ablation or microwave ablation, which require interstitial needle or antenna insertion. Therefore, DOX@PLA@AuPEG-MnP NPs could operate as an intelligent nanotheranostic agent, which is very helpful for accurately visualizing the size and location of the tumor, guiding and monitoring the therapeutic process, as well as synergistically treating cancer through a single agent. 


\section{Supplementary Material}

Figure S1 - S8; Table S1.

http://www.thno.org/v04p0858s1.pdf

\section{Acknowledgment}

This work was financially supported by National Natural Science Foundation for Distinguished Young Scholars (No. 81225011), State Key Program of National Natural Science of China (Grant No. 81230036), National Natural Science Foundation of China (No. 81371580 and 21273014) and Natural Science Foundation of Heilongjiang Province for Distinguished Young Scholars (JC201112).

\section{Competing Interests}

The authors have declared that no competing interest exists.

\section{References}

1. Huebsch N, Mooney DJ. Inspiration and application in the evolution of biomaterials. Nature. 2009; 462: 426-32.

2. Timko BP, Dvir T, Kohane DS. Remotely triggerable drug delivery systems. Adv Mater. 2010; 22: 4925-43.

3. Schroeder A, Honen R, Turjeman K, Gabizon A, Kost J, Barenholz Y. Ultra-sound triggered release of cisplatin from liposomes in murine tumors. J Control Release. 2009; 137: 63-8.

4. Ge J, Neofytou E, Cahill TJ, Beygui RE, Zare RN. Drug release from elec-tric-field-responsive nanoparticles. ACS Nano. 2012; 6: 227-33.

5. Baeza A, Guisasola E, Ruiz-Hernández E, Vallet-Regí M. Magnetically triggered multidrug release by hybrid mesoporous silica nanoparticles. Chem Mater. 2012; 24: 517-24.

6. Chen J. Saeki F, Wiley B J, Chang H, Cobb MJ, Li ZY, Au L, Zhang H, Kimmey MB, Li X, Xia YN. Gold nanocages: bioconjugation and their potential use as optical imaging contrast agents. Nano Lett. 2005; 5: 473-77.

7. Chen J, Wang D, Xi J, Au L, Siekkinen A, Warsen A, Li ZY, Zhang H, Xia YN, Li X. Immuno gold nanocages with tailored optical properties for targeted photothermal destruction of cancer cells. Nano Lett. 2007; 7: 1318-22.

8. Ke H, Wang J, Dai Z, Jin Y, Qu E, Xing Z, Guo C, Yue X, Liu J. Gold-nanoshelled microcapsules: a theranostic agent for ultrasound contrast imaging and photothermal therapy. Angew Chem Int Ed. 2011; 50: 3017-21.

9. Ma Y, Liang X, Tong S, Bao G, Ren Q, Dai Z. Gold nanoshell nanomicelles for potential magnetic resonance imaging, light-triggered drug release, and photothermal therapy. Adv Funct Mater. 2013; 23: 815-22.

10. Park H, Yang J, Lee J, Haam S, Choi IH, Yoo KH. Multifunctional nanoparticles for combined doxorubicin and photothermal treatments. ACS Nano. 2009; 3: 2919-26.

11. Choi WI, Kim JY, Kang C, Byeon CC, Kim YH, Tae G. Tumor regression in vivo by photothermal therapy based on gold-nanorod-loaded, functional nanocarriers. ACS Nano. 2011; 5: 1995-03.

12. Jang B, Park JY, Tung $\mathrm{CH}$, Kim IH, Choi Y. Gold nanorod-photosensitizer complex for near-Infrared fluorescence imaging and photodynam-ic/photothermal therapy In vivo. ACS Nano. 2011; 5: 1086-94.

13. Skrabalak SE, Chen J, Sun Y, Lu X, Au L, Cobley CM, Xia Y. Gold nanocages: synthesis, properties, and applications. Acc Chem Res. 2008; 41: 1587-95.

14. Skrabalak SE, Au L, Lu X, Li X, Xia Y. Gold nanocages for cancer detection and treatment. Nanomedicine. 2007: 2: 657-68.

15. Chen J, Yang M, Zhang Q, Cho EC, Cobley CM, Kim C, Glaus C, Wang LV, Welch MJ, Xia Y. Gold nanocages: a novel class of multifunctional nano-materials for theranostic applications. Adv Funct Mater. 2010; 20: 3684-94

16. Yang K, Hu L, Ma X, Ye S, Cheng L, Shi X, Li C, Li Y, Liu Z. Multimodal imaging guided photothermal therapy using functionalized graphene nanosheets anchored with magnetic nanoparticles. Adv Mater. 2012; 24: 1868-72.

17. Wang X, Wang C, Cheng L, Lee ST, Liu Z. Noble metal coated single-walled carbon nanotubes for applications in surface enhanced raman scattering im-aging and photothermal therapy. J Am Chem Soc. 2012; 134: 7414-22.

18. Yang K, Zhang S, Zhang G, Sun X, Lee ST, Liu Z. Graphene in mice: ultrahigh in vivo tumor uptake and efficient photothermal therapy. Nano Lett. 2010; 10: 3318-23.

19. Liu X, Tao H, Yang K, Zhang S, Lee ST, Liu Z. Optimization of surface chemistry on single-walled carbon nanotubes for in vivo photothermal ablation of tumors. Biomaterials. 2011; 32: 144-51.
20. Zha Z. Yue X, Ren Q, Dai Z. Uniform polypyrrole nanoparticles with high photothermal conversion efficiency for photothermal ablation of cancer cells. Adv Mater. 2013; 25: 777-82.

21. Tian Q, Tang M, Sun Y, Zou R, Chen Z, Zhu M, Yang S, Wang J, Wang J, Hu J. Hydrophilic flower-like CuS superstructures as an efficient $980 \mathrm{~nm}$ la-ser-driven photothermal agent for ablation of cancer cells. Adv Mater. 2011; 23: 3542-47.

22. Li YB, Lu W, Huang QA, Huang MA, Li C, Chen W. Copper sulfide nanoparticles for photothermal ablation of tumor cells. Nanomedicine. 2010; 5: 1161-71.

23. Zhou M, Zhang R, Huang MA, Lu W, Song SL, Melancon MP, Tian M, Liang D, Li CA. Chelator-free multifunctional $[64 \mathrm{Cu}] \mathrm{CuS}$ nanoparticle platform for simultaneous micro-PET/CT imaging and photothermal ablation therapy. J Am Chem Soc. 2010; 132: 15351-58.

24. You J, Zhang G, Li C. Exceptionally high payload of doxorubicin in hollow gold nanospheres for near-infrared light-triggered drug release. ACS Nano. 2010; 4: 1033-41.

25. Huschka R, Barhoumi A, Liu Q, Roth JA, Ji L, Halas NJ. Gene silencing by gold nanoshell-mediated delivery and laser-triggered release of antisense oligonucleotide and siRNA. ACS Nano. 2012; 6: 7681-91.

26. Xiao ZY, Ji CW, Shi JJ, Pridgen EM, Frieder J, Wu J, Farokhzad OC. DNA self-assembly of targeted near-infrared-responsive gold nanoparticles for cancer thermo-chemotherapy. Angew Chem Int Ed. 2012; 51: 11853-57.

27. Feshitan JA, Vlachos F, Sirsi SR, Konofagou EE, Borden MA. Theranostic Gd(III)-lipid microbubbles for MRI-guided focused ultrasound surgery. Biomaterials. 2012; 33: 247-55.

28. Yang XQ, Grailer JJ, Rowland IJ, Javadi A, Hurley SA, Matson VZ, Steeber DA, Gong SQ. Multifunctional stable and $\mathrm{pH}$-responsive polymer vesicles formed by heterofunctional triblock copolymer for targeted anti-cancer drug delivery and ultrasensitive MR imaging. ACS nano. 2010; 4: 6805-17.

29. Sanson C, Diou O, Thevenot I, Ibarboure E, Soum A, Brulet A, Miraux S, Thiaudiere E, Tan S, Brisson A, Dupuis V, Sandre O, Lecommandoux S. Doxorubicin loaded magnetic polymersomes: theranostic nanocarriers for MR imaging and magneto-chemotherapy. ACS nano. 2011; 5: 1122-40.

30. Zhang JF, Fatouros PP, Shu CY, Reid J, Owens LS, Cai T, Gibson HW, Long GL, Corwin FD, Chen ZJ, Dorn HC. High relaxivity trimetallic nitride (Gd3N) metallofullerene MRI contrast agents with optimized functionality. Bioconjugate Chem. 2010; 2: 610-15

31. Hartman KB, Laus S, Bolskar RD, Muthupilla R, Helm L, Toth E, Merbach AE, Wilson LJ. Gadonanotubes as ultrasensitive $\mathrm{pH}$-smart probes for magnetic resonance imaging. Nano Lett. 2008; 8: 415-19.

32. Sieber $M$, Lengsfeld $P$, Walter J, Schirmer $H$, Frenzel $T$, Siegmund $F$, Wein-mann H, Pietsch H. Gadolinium-based contrast agents and their potential role in the pathogenesis of nephrogenic systemic fibrosis: the role of excess ligand. J Magn Reson Imaging. 2008; 27: 955-62.

33. Kessinger CW, Togao O, Khemtong C, Huang G, Takahashi M, Gao J. Investigation of in vivo targeting kinetics of alpha(v)beta(3)-Specific superparamagnetic nanoprobes by time-resolved MRI. Theranostics. 2011; 1: 263-73.

34. Kim T, Momin E, Choi J, Yuan K, Zaidi H, Kim J, Park M, Lee N, McMahon MT, Quinones-Hinojosa A, Bulte JWM, Hyeon T, Gilad AA. Mesoporous silica-coated hollow manganese oxide nanoparticles as positive T1 contrast agents for labeling and MRI tracking of adipose-derived mesenchymal stem cells. J Am Chem Soc. 2011; 133: 2955-61.

35. Wang S, Westmoreland T. Correlation of relaxivity with coordination number in six-, seven-, and eight coordinate $\mathrm{Mn}$ (II) complexes of pendant arm cyclen derivatives. Inorg Chem. 2009; 48: 719-27.

36. Zhang Z, He R, Yan K, Guo QN, Lu YG, Wang XX, Lei H, Li ZY. Synthesis and in vitro and in vivo evaluation of manganese(III) porphyrin-dextran as a novel MRI contrast agent. Bioorg Med Chem Lett. 2009; 19: 6675-78.

37. Zong YD, Wang XH, Goodrich KC, Mohs AM, Parker DL, Lu ZR. Con-trast-enhanced MRI with new biodegradable macromolecular Gd(III) com-plexes in tumor-bearing mice. Magn Reson Med. 2005; 53: 835-42.

38. Xiao L, Xiong XQ, Sun XH, Zhu YH, Yang H, Chen HB, Gan L, Xu HB, Yang $\mathrm{XL}$. Role of cellular uptake in the reversal of multidrug resistance by PEG-b-PLA polymeric micelles. Biomaterials. 2011; 32: 5148-57.

39. Lassalle V, Ferreira ML. PLA nano- and microparticles for drug delivery: an overview of the methods of preparation. Macromol Biosci. 2007; 7: 767-83.

40. Aso Y, Yoshioka S, Li Wan Po A, Terao T. Effect of temperature on mecha-nisms of drug-release and matrix degradation of poly(D,L-lactide) micro-spheres. J Control Release. 1994; 31: 33-39.

41. Hribar KC, Lee MH, Lee D, Burdick JA. Enhanced release of small molecules from near-infrared light responsive polymer-nanorod composites. ACS Nano. 2011; 5: 2948-56

42. Jing LJ, Liang XL, Li XD, Yang YB, Dai ZF. Covalent attachment of Mn-porphyrin onto doxorubicin-loaded poly(lactic acid) nanoparticles for potential magnetic resonance imaging and $\mathrm{pH}$-sensitive drug delivery. Acta Biomater. 2013; 9: 9434-41.

43. Brown KR, Natan MJ. Hydroxylamine seeding of colloidal Au nanoparticles in solution and on surfaces. Langmuir. 1998; 14: 726-28.

44. Ji T, Lirtsman VG, Avny Y, Davidov D. Preparation, characterization, and application of Au-shell/polystyrene beads and Au-shell/magnetic beads. Adv Mater. 2001; 13: 1253-56.

45. Hanahan D, Weinberg RA. The hallmarks of cancer. Cell. 2000; 100: 57-70. 
46. Brautboucher F, Pichon J, Rat P, Adolphe M, Aubery M, Font JJ. A non-isotopic, highly sensitive, fluorimetric, cell-cell adhesion microplate assay using calcein AM-labeled lymphocytes. Immunol Methods. 1995; 178: 41-51.

47. Guo CX, Wang JL, Dai ZF. Selective content release from light-responsive microcapsules by tuning the surface plasmon resonance of gold nanorods. Microchimica Acta. 2011; 173: 375-82.

48. Yang K, Zhang S, Zhang G, Sun X, Lee ST, Liu Z. Graphene in mice: ultrahigh In vivo tumor uptake and efficient photothermal therapy. Nano Lett. 2010; 10: 3318-23.

49. Yang K, Wang JM, Zhang S, Zhang YJ, Lee ST, Liu Z. In vivo pharmacokinetics, long-term biodistribution, and toxicology of PEGylated graphene in mice. ACS nano. 2011; 5: 516-22.

50. Zhen MM, Zheng JP, Ye L, Li SM, Jin C, Li K, Qiu D, Han HB, Shu CY, Yang YJ, Wang CR. Maximizing the relaxivity of Gd-complex by synergistic effect of HSA and carboxylfullerene. ACS Appl Mater Interfaces. 2012; 4: 3724-29.

51. Garimella PD, Datta A, Romanini DW, Raymond KN, Francis MB. Multivalent, high-relaxivity MRI contrast agents using rigid cysteine-reactive gadolinium complexes. J Am Chem Soc. 2011; 133: 14704-9.

52. Liu YY, Miyoshi H, Nakamura M. Nanomedicine for drug delivery and imaging: a promising avenue for cancer therapy and diagnosis using targeted functional nanoparticles. Int J Cancer. 2007; 120: 2527-37.

53. Rhyner MN, Smith AM, Gao XH, Mao H, Yang LL, Nie SM. Quantum dots and multifunctional nanoparticles: new contrast agents for tumor imaging. Nanomedicine. 2006; 1: 209-17. 